\title{
Lu Xun e a anatomia de um povo
}

Márcia Schmaltr

Ainda me lembro da sensação de estranhamento que me causou o olhar apático de AQ no seu Retrato Póstumo desenhado pelo cartunista Feng Zikai 丰子 恺 (1898-1975) em 1986, mas somente conheci Lu Xun 鲁迅, pseudônimo de Zhou Shuren 周树人 (1881-1936), depois da visita à sua terra natal, Shaoxing, em 2002. Antes não fora possível, já que o autor era censurado em Taiwan, onde vivi boa parte de minha infância. Contudo, a sua obra era lida e investigada veladamente nos ambientes universitários de Formosa, devido ao autor ter levado a fala cotidiana à escrita e introduzido o fluxo de consciência aos personagens - até então inexistentes na literatura chinesa.

Considerado um dos fundadores da literatura moderna chinesa, é um dos escritores do século XX que deixou o maior volume de escritos, que gerou um campo de estudo literário próprio e exerceu influência sobre as gerações de escritores seguintes. Um dos maiores prêmios literários concedidos no país leva o seu nome e, além de cânone da literatura universal, é também um símbolo de patriotismo e de espírito democrático, por almejar libertar os chineses do estado de apatia em que se encontravam no final do século XIX e início do século XX.

Geralmente o ocidental ao ler os textos clássicos confucianos associa os seus ditos às virtudes silenciosas de paciência, pacifismo e honra, à regra de ouro, à reverência aos ancestrais, aos idosos e às pessoas cultas, porém, se essa visão for analisada no seu contexto sociopolítico, percebe-se que a preferência pela velhice à juventude, pelo passado ao presente, pela autoridade estabelecida à inovação criou uma ordem social por meio da obediente autosubordinação que deixaram as suas marcas na China até hoje (FAIRBANK; GOLDMAN, 2006). Naquele período, Lu Xun junto à maioria da elite intelectual queria acabar com esse estado de coisas e impingir uma nova ordem, com ares mais científicos e de menos superstição. 
Por isso, a leitura de Lu Xun é um passo para a compreensão da inteligentsia chinesa. A sua leitura ajuda a entender as duas primeiras décadas do século XX, época de transição chinesa do regime monárquico para o republicano anterior a 1949. A prosa ficcional do Autor é um retrato de um período atribulado, de contradição, de mudança de costumes e de modernização. Para a leitura de Lu Xun, porém, faz-se necessário uma retrospectiva histórica em algumas linhas para situar o leitor.

Em 1644, o exército manchu invade a China, dizima a corte da dinastia Ming (1368-1644) e dá início a dinastia Qing (1644-1911). A dinastia manchuriana marcou a sua entrada na Planície Central com crueldade e terror, especialmente ao impor aos homens a adoção da tonsura manchu distintiva - o uso da trança com a parte frontal da cabeça raspada - símbolo da sujeição leal à etnia da região nordeste. Contudo, a nova dinastia manteve as convenções sociais e leis anteriores - inclusive a proibição de comércio com o exterior. Vários levantes e insurreições da etnia Han, população majoritária chinesa, ocorreram durante os dois séculos seguintes e os revoltosos eram exemplarmente reprimidos. No século XIX, o regime Qing é arrasado por derrotas sucessivas: a Guerra do Ópio e a invasão das oito potências estrangeiras obrigou-o a restabelecer as relações externas; as contenções às inúmeras rebeliões internas aumentavam as despesas nacionais, somada à corrupção e ao peculato governamental generalizado levaram à queda do regime pela Revolução Republicana de 1911. A esperança da República, proclamada em 1912, foi destruída pelo golpe militar dos senhores da guerra, que tentou restabelecer a monarquia e os preceitos confucianos. Em 1915, o Japão apresenta à China 21 exigências muito agressivas para instaurar uma espécie de protetorado japonês ao país, que embora não tenha sido bem-sucedido, muitos estudantes foram enviados para absorver os métodos científicos de pensamento e crítica, e intensificou o nacionalismo chinês moderno.

Como um homem de seu tempo, Lu Xun fez parte de uma geração que recebeu inicialmente uma educação de moldes confucianos e mais tarde contatou com os estudos científicos no exterior. O Escritor teve de libertar-se de dois preceitos: "primeiro, do pensamento mumificado da tirania patriarcal e do sistema familiar do velho confucionismo, segundo, da confusão política e cultural contida no 'novo aprendizado"' (FAIRBANK; GOLDMAN, 2006). Para a primeira geração republicana, esse aprendizado significou a destruição de sua formação intelectual com o qual tinha formado a sua identidade. Lu Xun para se emancipar dos desacreditados laços com o confucionismo, que o deixara temeroso e à deriva, optou pela crença na ciência, especialmente o darwinismo, ao ler Huxley, e dedicar-se à revolução literária - o Movimento da Nova Cultura. 
A sua maior colaboração foi de dissecar o espírito de seu povo através de sua pena mordaz expondo a questão da identidade étnica em seus contos através de uma linguagem vernácula, acessível ao homem comum. Embora idealista, era herdeiro de uma tradição estratificada e imprimiu em seus escritos um tom de amargura messiânica, em uma linguagem ácida carregada de melancolia em uma análise fria e racional darwinista, em uma trama essencialmente trágica, como aponta Sun (2007, p. 136).

Para traduzir Lu Xun tive de mergulhar numa leitura crítica da história chinesa e apreensão do subentendido da narrativa. Ultrapassada a etapa de compreensão, o desafio foi normalizar o estilo do autor ao português. Os contos completos de Lu Xun aguarda a publicação pela editora L\&PM. Trago aos leitores minha tradução do prefácio de Nàbăn [O Chamado] (1923), que o autor se apresenta e revela seu propósito de mudar o estado das coisas da China através de sua pena.

\section{Prefácio do autor à primeira edição de $O$ Chamado}

Também eu, quando jovem, tive muitos sonhos, a maioria dos quais esqueci, sem lamentar. As lembranças do passado tanto podem fazer alguém feliz como ao contrário, muitas vezes fazem com que fiquemos atados a tempos de solidão, o que não tem muito sentido. Embora me esforce, não consigo esquecê-las por completo e essas vieram a dar origem a $O$ Chamado.

Por mais de quatro anos, eu ia quase todos os dias do penhor ao herbanário. A minha idade já não me recordo, contudo lembro-me daquele balcão que era da minha altura, enquanto o do penhor era o dobro de mim. Eu, envergonhado, ia ao balcão com o dobro da minha altura para trocar roupas ou joias por dinheiro e ia até o balcão da minha altura para comprar ervas medicinais para o meu pai, que estava muito doente. Depois de voltar para a casa, tinha ainda de me ocupar com o preparo da medicação, porque a prescrição era tão exótica quanto à fama do médico que a receitava: raiz de babosa invernal, cana-de-açúcar exposta à geada por três anos, um casal de grilos em primeira cópula, semente de ardísia..., a maioria dos ingredientes era difícil de conseguir. Entretanto, de nada adiantou, o meu pai foi de mal a pior e acabou por falecer.

Acreditei que para quem desabasse da bonança à desventura seria mais fácil de reconhecer a verdadeira face das pessoas durante a trajetória da vida. $\mathrm{Eu}$ quis ir à $\mathrm{N}$ para estudar em $\mathrm{K}^{1}$, trilhar caminhos adversos, fugir para o

1 Academia Naval de Kiangnan em Nanjing (N.T.). 
estrangeiro e ir à procura de pessoas diferentes. Minha mãe não tinha como me impedir, então, arranjou e entregou para mim oito yuans para a viagem e disse chorando: "Faça como quiser". Pois o caminho normal, naquela época, seria seguir os estudos clássicos e fazer os exames imperiais, e qualquer um que fosse estudar no exterior era considerado um fracasso social que, num ato de desespero, vendeu a alma ao diabo estrangeiro. Claro que ela também estava triste por não me ter mais ao seu lado, mas, naquela época, eu não tinha como me importar com essas coisas.

Finalmente fui a $\mathrm{N}$ e entrei em $\mathrm{K}$, e foi nessa escola que descobri epistemologia, aritmética, geografia, história, desenho e educação física. Não tinha fisiologia no curso, mas lemos o Novo Curso do Corpo Humano e o Ensaio de Química $e$ Higiene em edições xilográficas, entre outros do gênero. Ainda me lembro das discussões sobre as prescrições médicas chinesas e, comparado ao que se sabe hoje, me dei conta de que os clínicos chineses não passavam de charlatões, mal-intencionados ou não, e tive piedade dos doentes e de seus familiares que sofrem em suas mãos. O contato com os livros de história fez com que eu soubesse que a Reforma Japonesa teve origem, em grande parte, devido à introdução no país das ciências médicas ocidentais.

Essas noções superficiais levaram-me a uma faculdade de medicina no interior do Japão. Meu sonho era perfeito. Pretendia, quando voltasse ao meu país, salvar do sofrimento os doentes desenganados como meu pai, servir como médico no exército durante a guerra, enquanto promovia o pensamento científico entre os meus compatriotas.

Desconheço as quantas anda a metodologia de ensino da microbiologia, mas na época as aulas teóricas eram dadas através de slides. Às vezes, o conteúdo previsto para o dia era concluído mais cedo, então o professor mostrava fotos de noticiário para passar o tempo restante da aula. Como estávamos no período da guerra russo-japonesa, muitos slides eram sobre isso e eu me juntava aos aplausos e vivas dos colegas de aula. Até que houve uma vez em que fui surpreendido ao ver um chinês amarrado, circundado por outros chineses, feito espectadores. Apesar de fortes, aparentavam uma expressão de apatia. Segundo a narração do professor, o homem amarrado fora considerado um espião russo e estava prestes a ser decapitado publicamente pelos militares japoneses, para servir de exemplo aos que assistiam à execução.

$\mathrm{O}$ ano letivo não havia terminado, e eu já estava em Tóquio; pois, a partir daquele episódio, passei a acreditar que medicina não era o mais importante para mudar a China. Afinal, um povo ignorante, mesmo forte e com saúde, no máximo podia servir como um espectador de tais demonstrações públicas sem sentido e 
ninguém lamentaria a falta de um desses, mesmo se morresse por doença. Por conseguinte, o fundamental era a mudança das mentes, e julguei que a melhor maneira de se fazer isso, seria através das artes. Então planejei promover um movimento literário.

A maioria dos estudantes chineses em Tóquio se dedicava ao direito, à ciência política, à física, à química, até mesmo às ciências da informação ou às engenharias, e ninguém estudava literatura ou artes. Nessa atmosfera indiferente, tive a sorte de encontrar parceiros e consegui reunir outras pessoas necessárias à tarefa. Após discussões, decidimos iniciar com o lançamento de uma revista, cujo nome deveria remeter ao nascimento de algo novo. Talvez porque nós tivéssemos uma inclinação aos clássicos, a batizamos de Xinsheng (Vida Nova).

A data de lançamento de Vida Nova se aproximava, e alguns colaboradores nos abandonaram, a seguir os recursos desapareceram e no final sobraram apenas três indivíduos sem nenhum tostão. Tendo em vista que o nosso projeto começara em uma hora imprópria, obviamente que não culpamos ninguém pelo seu fracasso. Depois, cada um foi atrás de seu destino e objetivos, e não pudemos mais ficar juntos conversando e sonhando sobre o amanhã. Esse foi o grand finale de Vida Nova que não chegou a nascer.

Senti uma grande decepção e, por ser inexperiente, não entendia que há um processo para a transformação de um estado de coisas. Mais tarde, acreditei ser apenas necessário um homem inflar-se de coragem e seguir em frente, quando a ideia tinha apoio e, caso houvesse oposição, apenas resistir. Contudo, a dura realidade foi que o meu clamor não obteve resposta alguma - nem de apoio e nem de oposição -, como se abandonado estivesse, em um imenso deserto, fui tomado pela solidão.

Esse sentimento de solidão crescia dia após dia, como uma víbora que se entrelaça na alma. Apesar da minha enorme tristeza, não me indignei, porque aquela experiência fez com que eu refletisse e enxergasse a mim mesmo: não era nenhum herói, o meu chamado não mobilizava ninguém.

Eu estava agonizando e tinha de dissipar a minha solidão. Utilizei de várias artimanhas na tentativa de anestesiar a minha alma: camuflei-me em meio ao povo e mergulhei no passado. Mais tarde, testemunhei os mais solitários e tristes acontecimentos, dos quais não quero me lembrar, e me conforta que essas lembranças se desintegrarão comigo a sete palmos do chão. Os meus esforços para me tornar indiferente não foram de todo em vão - perdi o entusiasmo e o fervor da minha juventude. 
Existem três quartos na pensão em $\mathrm{S}^{2}$ e conta-se que em um deles vivia uma mulher que se enforcou na sófora do pátio - hoje é impossível subir na árvore devido à altura que atingiu, enquanto o quarto da suicida permanecera vazio, até eu ir morar ali e passar o tempo compilando epígrafes inscritas em pedras antigas durante vários anos. Não me deparei com maiores dificuldades e essa pesquisa me absorveu muito. Recebia poucas visitas, contudo a minha vida foi se esvaindo, e esse era o meu único desejo. Havia muitos mosquitos nas noites de verão, e eu ficava sentado embaixo da sófora me abanando e espreitando os pedacinhos de céu que se revelavam entre as folhas, enquanto lagartas frias caíam de tempos em tempos na minha nuca.

Naquela época, um velho amigo chamado Jin Xinyi ${ }^{3}$ vinha me visitar, largava a sua velha carteira de couro sobre a mesa surrada, tirava o casaco e sentava à minha frente, com seu coração pululante de medo dos cachorros da rua.

- Para que serve copiar essas pedras? - perguntou-me inquisitivo numa noite, ao folhear meu caderno.

- Não serve para nada.

- Então qual o sentido de copiá-las?

- Nenhum.

- Por que não escreve alguma coisa?...

Compreendi. Ele e outros estavam organizando a revista Nova Juventude, e como não conseguiam arrecadar o apoio e nem a oposição de ninguém, percebi que se sentiam solitários, então comentei:

- Imagine uma casa de ferro, sem janela nenhuma e absolutamente indestrutível. Dentro dela, dormem muitas pessoas, que logo morrerão sufocadas, mas não entrarão em pânico, já que passarão do sono direto à morte. Então, nesse momento, você dá um grito e consegue acordar alguns de sono mais leve, fazendo com que essa minoria infeliz venha a experimentar o sofrimento inevitável da hora final. Como você se sentiria? Acha que estaria fazendo uma boa ação?

- Desde que se acordassem, ainda haveria uma esperança de saírem da casa. $\mathrm{E}$ isso você não pode negar-lhes.

É verdade. Apesar de minhas convicções, não poderia negar a esperança, porque ela está vinculada ao futuro. Não poderia usar as minhas próprias evidências

2 Pensão do condado de Shaoxing localizado próximo do bairro Xuanwumen em Beijing, a qual o autor residiu entre 1912 e 1919 quando trabalhou no Ministério da Educação (N.T.).

3 Pseudônimo de Qian Xuantong (1887-1939), um dos líderes do Movimento Quatro de Maio (1919) e propositor da reforma da língua chinesa (N.T.). 
para refutá-la. Assim, aceitei escrever para a revista, e o texto resultou no O Diário de um Louco. A partir de então, não consegui mais parar. Ao pedido de amigos, reuni mais dez contos, no livro que o leitor tem em mãos.

$\mathrm{Eu}$, que acreditava ser impossível me expressar, mas talvez por ainda lembrar aqueles dias de solidão e tristeza, às vezes não me contenho e grito para o guerreiro que galopa pelo deserto, na intenção de confortá-lo e encorajá-lo a sempre seguir em frente. Não me importo se o meu grito é bravo ou triste, repugnante ou ridículo. E tendo em vista que é um chamamento, é necessário que se atendam as ordens do comandante. Por isso, em $O$ Remédio, pus uma coroa de flores no túmulo de Yu'er e não contei que a Mulher de Dan Quatro não sonhou com o filho em $O$ Amanhã, porque naquela época, o comandante era contra o pessimismo. Quanto a mim, também não quis passar adiante o sofrimento de minha solidão, para não contaminar os jovens sonhadores; pois, também fui sonhador quando jovem.

Dessa forma, pode-se imaginar a distância entre os meus escritos e a Arte, mas me sinto afortunado por serem considerados contos e por ter a oportunidade de reuni-los em livro. De qualquer maneira, há de se considerar tudo isso como obra do acaso; embora tal sorte tenha me trazido a intranquilidade, fico feliz em saber que ainda existam leitores no mundo.

Portanto, reuni os meus contos que foram publicados e devido aos motivos expostos acima denominei essa coleção de Naban (O Chamado).

Lu Xun

Beijing, 3 de dezembro de 1922.

\section{《呐喊》自序}

我在年青时候也曾经做过许多梦, 后来大半忘却了, 但自己也并 不以为可惜。所谓回忆者, 虽说可以使人欢欣, 有时也不免使人寂寞, 使精神的丝缕还牵着己逝的寂寞的时光, 又有什么意味呢, 而我偏苦于 不能全忘却, 这不能全忘的一部分, 到现在便成了《呐喊》的来由。

我有四年多, 曾经常常, 一一几乎是每天, 出入于质铺和药店里, 年纪可是忘却了, 总之是药店的柜台正和我一样高, 质铺的是比我高一 倍, 我从一倍高的柜台外送上衣服或首饰去, 在侮葽里接了钱, 再到一 样高的柜台上给我久病的父亲去买药。回家之后, 又须忙别的事了, 因 为开方的医生是最有名的, 以此所用的药引也奇特: 冬天的芦根, 经霜 三年的甘蔗, 蟋蟀要原对的, 结子的平地木, ......多不是容易办到的东 西。然而我的父亲终于日重一日的亡故了。 
有谁从小康人家而坠入困顿的么, 我以为在这途路中, 大概可以看 见世人的真面目; 我要到 $N$ 进 $\mathrm{K}$ 学堂去了, 仿佛是想走异路, 逃异地, 去 寻求别样的人们。我的母亲没有法, 办了八元的川资, 说是由我的自便; 然而伊哭了, 这正是情理中的事, 因为那时读书应试是正路, 所谓学洋 务, 社会上便以为是一种走投无路的人, 只得将灵魂卖给鬼子, 要加倍 的奚落而且排斥的, 而况伊又看不见自己的儿子了。然而我也顾不得这 些事, 终于到 $\mathrm{N}$ 去进了 $\mathrm{K}$ 学堂了, 在这学堂里, 我才知道世上还有所谓格 致, 算学, 地理, 历史, 绘图和体操。生理学并不教, 但我们却看到些 木版的《全体新论》和《化学卫生论》之类了。我还记得先前的医生的议 论和方药, 和现在所知道的比较起来, 便渐渐的悟得中医不过是一种有意 的或无意的骗子, 同时又很起了对于被骗的病人和他的家族的同情; 而 且从译出的历史上, 又知道了日本维新是大半发端于西方医学的事实。

因为这些幼稚的知识, 后来便使我的学籍列在日本一个乡间的医 学专门学校里了。我的梦很美满, 预备卒业回来, 救治象我父亲似的 被误的病人的疾苦, 战争时候便去当军医, 一面又促进了国人对于维 新的信仰。我已不知道教授微生物学的方法, 现在又有了怎样的进步 了, 总之那时是用了电影, 来显示微生物的形状的, 因此有时讲义的一 段落已完, 而时间还没有到, 教师便映些风景或时事的画片给学生看, 以用去这多余的光阴。其时正当日俄战争的时候, 关于战事的画片自然 也就比较的多了, 我在这一个讲堂中, 便须常常随喜我那同学们的拍手 和喝采。有一回, 我竟在画片上忽然会见我久违的许多中国人了, 一个 绑在中间, 许多站在左右, 一样是强壮的体格, 而显出麻木的神情。据 解说, 则绑着的是替俄国做了军事上的侦探, 正要被日军砍下头颅来示 众, 而围着的便是来赏鉴这示众的盛举的人们。

这一学年没有完毕, 我已经到了东京了, 因为从那一回以后, 我便 觉得医学并非一件紧要事, 凡是愚弱的国民, 即使体格如何健全, 如何 茁壮, 也只能做毫无意义的示众的材料和看客, 病死多少是不必以为不 幸的。所以我们的第一要著, 是在改变他们的精神, 而善于改变精神的 是, 我那时以为当然要推文艺, 于是想提倡文艺运动了。在东京的留学 生很有学法政理化以至警察工业的, 但没有人治文学和美术; 可是在冷 淡的空气中, 也幸而寻到几个同志了, 此外又邀集了必须的几个人, 商 量之后, 第一步当然是出杂志, 名目是取 “新的生命” 的意思, 因为我 们那时大抵带些复古的倾向，所以只谓之《新生》。

《新生》的出版之期接近了, 但最先就隐去了若千担当文字的 人, 接着又逃走了资本, 结果只剩下不名一钱的三个人。创始时候既己 背时, 失败时候当然无可告语, 而其后却连这三个人也都为各自的运命 所驱策, 不能在一处纵谈将来的好梦了, 这就是我们的并未产生的《新 生》的结局。 
我感到未尝经验的无仰, 是自此以后的事。我当初是不知其所以然 的; 后来想, 凡有一人的主张, 得了赞和, 是促其前进的, 得了反对, 是促其奋斗的, 独有叫喊于生人中, 而生人并无反应, 既非赞同, 也无 反对, 如置身毫无边际的荒原, 无可措手的了, 这是怎样的悲哀呵, 我 于是以我所感到者为寂寞。

这寂寞又一天一天的长大起来, 如大毒蛇, 缠住了我的灵魂了。

然而我虽然自有无端的悲哀, 却也并不愤潄, 因为这经验使我反 省, 看见自己了：就是我决不是一个振臂一呼应者云集的英雄。

只是我自己的寂寞是不可不驱除的, 因为这于我太痛苦。我于是用 了种种法, 来麻醉自己的灵魂, 使我沉入于国民中, 使我回到古代去, 后来也亲历或旁观过几样更寂寞更悲哀的事, 都为我所不愿追怀, 甘心 使他们和我的脑一同消灭在泥土里的, 但我的麻醉法却也似乎已经奏了 功, 再没有青年时候的慷慨激昂的意思了。

$\mathrm{S}$ 会馆里有三间屋, 相传是往昔曾在院子里的槐树上缢死过一个女 人的, 现在槐树已经高不可攀了, 而这屋还没有人住; 许多年, 我便寓 在这屋里钞古碑。客中少有人来, 古碑中也遇不到什么问题和主义, 而 我的生命却居然暗暗的消去了, 这也就是我惟一的愿望。夏夜, 蚁子多 了, 便摇着蒲扇坐在槐树下, 从密叶缝里看那一点一点的青天, 晚出的 槐虫又每每冰冷的落在头颈上。

那时偶或来谈的是一个老朋友金心异, 将手提的大皮夹放在破 桌上, 脱下长衫, 对面坐下了, 因为怕狗, 似乎心房还在怦怦的跳动。

“你钞了这些有什么用? ”有一夜, 他翻着我那古碑的钞本, 发 了研究的质问了。

“没有什么用。”

“那么, 你钞他是什么意思呢?”

“没有什么意思。”

“我想，你可以做点文章......”

我懂得他的意思了，他们正办《新青年》，然而那时仿佛不特没 有人来赞同, 并且也还没有人来反对, 我想, 他们许是感到寂寞了, 但是说：

“假如一间铁屋子, 是绝无窗户而万难破毁的, 里面有许多熟睡的 人们, 不久都要间死了, 然而是从昏睡入死灭, 并不感到就死的悲哀。 现在你大㗒起来, 惊起了较为清醒的几个人, 使这不幸的少数者来受无 可挽救的临终的苦楚, 你倒以为对得起他们么?”

“然而几个人既然起来, 你不能说决没有毁坏这铁屋的希望。”

是的, 我虽然自有我的确信, 然而说到希望, 却是不能抹杀的, 
因为希望是在于将来, 决不能以我之必无的证明, 来折服了他之所谓可 有, 于是我终于答应他也做文章了, 这便是最初的一篇《狂人日记》。 从此以后, 便一发而不可收, 每写些小说模样的文章, 以敷衍朋友们的 嘱托, 积久了就有了十余篇。

在我自己, 本以为现在是已经并非一个切迫而不能已于言的人了, 但或者也还未能忘怀于当日自己的寂寞的悲哀罢, 所以有时候仍不免呐 喊几声, 聊以慰藉那在寂寞里奔驰的猛士, 使他不惮于前驱。至于我的 喊声是勇猛或是悲哀, 是可憎或是可笑, 那倒是不暇顾及的; 但既然是 呐喊, 则当然须听将令的了, 所以我往往不恤用了曲笔, 在《药》的瑜 儿的坟上平空添上一个花环, 在《明天》里也不叙单四嫂子竟没有做到 看见儿子的梦, 因为那时的主将是不主张消极的。至于自己, 却也并不 愿将自以为苦的寂寞, 再来传染给也如我那年青时候似的正做着好梦的 青年。

这样说来, 我的小说和艺术的距离之远, 也就可想而知了, 然而 到今日还能蒙着小说的名, 甚而至于且有成集的机会, 无论如何总不能 不说是一件侥幸的事, 但侥幸虽使我不安于心, 而悬揣人间暂时还有读 者, 则究竟也仍然是高兴的。

所以我竟将我的短篇小说结集起来, 而且付印了, 又因为上面所 说的缘由, 便称之为《呐喊》。

$$
\text { 一九二二年十二月三日, 鲁迅记于北京。 }
$$

\section{Referências}

FAIRBANK, John King; GOLDMAN, Merle. China - Uma Nova História, tradução de Marisa Motta. Porto Alegre: L\&PM, 2006.

SUN, Yu. 《鲁迅与周作人》Lu Xun yu Zhou Zuoren [Lu Xun e Zhou Zuoren]. Shenyang: Editora do Povo de Liaoning, 2007.

ZHOU, Shuren (alias Lu Xun). 鲁迅全集 Lu Xun quanji [Obra completa de Lu Xun]. Pequim: Editora do Povo, 1973. 